\title{
Motivation, Measurement and Rewards from a Performance Evaluation Perspective
}

\author{
Eduardo Schiehll \\ Raymond Morissette
}

\section{RESUMO}

Novos ambientes de produção, competição global e novas tecnologias de informação são alguns dos tópicos utilizados para enfatizar que as organizações necessitam de mudanças no seu processo de avaliação de desempenho. A relação entre o grau de confiança na informação contábil e o comportamento individual tem sido investigada em pesquisas na área de contabilidade comportamental. Por outro lado, a perspectiva informacional estuda como o nível de desempenho organizacional depende da disponibilidade de indicadores de desempenho que permitam identificar a relação de causa-efeito entre decisões e resultados. Na tentativa de melhor compreender como estas teorias estão relacionados à avaliação de desempenho organizacional, este ensaio oferece uma discussão teórica sobre os seguintes tópicos: Quais são as dimensões da avaliação de desempenho organizacional? Como e em que extensão o sistema de remuneração está relacionado à avaliação de desempenho? Por que a definição de critérios para avaliação de desempenho organizacional é uma tarefa complexa?

Palavras-chaves: contabilidade comportamental; avaliação de desempenho; remuneração; critérios de desempenho.

\begin{abstract}
The new manufacturing environment, global competition and information technology represent issues often used to justify the need for organizations to change how they assess their overall performance. Behavioral accounting research provides insights on relationships between the level of reliance on accounting information for performance evaluation and individual behavior. From another perspective, agency studies investigate how organization's ability to function successfully is determined by the availability of performance information upon which managers can act. In an attempt to better understand how and why these theories may shed new lights on the evaluation of organizational overall performance, this paper discusses three related issues being: What are the main dimensions of organizational performance? How and to which extent is reward system related to performance evaluation? Why is performance criteria definition a difficult task?
\end{abstract}

Key words: behavioral accounting; performance evaluation; reward; performance criteria. 


\section{INTRODUCTION}

The expression performance is often used and has become a fashionable topic in management accounting literature. The new manufacturing environment, global competition and information revolution are some of the issues that have been used to raise the relevance of the subject and the argument that organizations need changing in the way they assess their overall performance. Despite its prominent place as a research topic, however, accounting literature seems to lack an objective definition and a consensus of what exactly is a Performance Measurement System (PMS). Books and articles about PMS introduce the subject by arguing about why organizations need to evaluate performance, why they need to link performance measures with strategy or even emphasize the different dimensions of organizational performance without elaborating a clear definition of what is a PMS, and where it resides in terms of accounting and management control system. Among the literature covered for this paper, only one explicit definition of performance measurement system was found. According to Atkinson, Waterhouse and Wells (1997, p. 26): "The performance measurement system is the tool the company uses to monitor those contractual relationships [with stakeholders]".

Using a social contract model of organization ${ }^{(1)}$, those authors developed a stakeholder approach to strategic performance measurement. Intrinsic and extrinsic contracts among the organization and its stakeholders (owners, customers, suppliers, employees and community) are the main concern of this framework. This approach automatically links performance with the issues of communication of goals, conflict of interest, control and reward. In this sense the following question seems relevant: Is PMS an information system that helps make decisions and monitor organizational goals, a behavioral control mechanism that motivates, integrates and rewards subordinates or both?

The literature shows that both the information and behavioral perspectives (separately or together) can be used to study and justify the use of PMS in organizations. The relation between the degree of reliance on accounting information for performance evaluation ${ }^{(2)}$ and individual behavior (functional or dysfunctional) has been examined in behavioral accounting research. The information perspective, on the other hand, studies how an organization's ability to function successfully depends on the availability of information which properly track business performance upon which its managers can act. 
Hypothesizing that the organization's overall performance depends in a certain way on how individuals perform their specific tasks, economic and behavioral theories may show some links and possibly some interdependence when used to study performance measurement. In its last section this article presents Figure 1, which summarizes this idea and the general proposition about the necessary alignment between performance criteria and reward system. Hence, in an attempt to better understand how and why the assumptions addressed by economic and behavioral theories are related to performance, the present article raises some theoretic discussion about the following issues:

.What are the dimensions of the organizational performance?

. How and to what extent reward system is related to the PMS?

.Why is performance criteria definition a difficult task?

\section{The Dimensions of Organizational Performance}

Organizational performance is very often associated with expressions like success, effectiveness, maximized utility, improvement, productivity, accountability etc. These different expressions either illustrate its multidisciplinary and the difficulty authors face when defining and characterizing organizational performance. In addition, the measures used to assess performance vary depending on schools of thought and research methodology used. Given that, the emergent research question is how to integrate all this diversity of measures (see Table 1 below) to obtain a more complete surrogate of the organizational overall performance.

Table 1: Performance Measures Used by Various Research Disciplines

\begin{tabular}{|l|l|}
\hline \multicolumn{1}{|c|}{$\begin{array}{c}\text { Research } \\
\text { Area }\end{array}$} & \multicolumn{1}{c|}{ Typical Performance Measures } \\
\hline Accounting & Current Ratio, Quick Ratio, Net Working Capital, Cash Flow. \\
\hline Economics & Profits, Sales Growth. \\
\hline Finance & Stock Prices, EPS, Net Income, ROI. \\
\hline Marketing & Sales Growth, Market Share, Brand Awareness. \\
\hline Organizational Behavior & Employee Satisfaction, Turnover Rate, Span of Control \\
\hline Production & Cost/Unit, Inventory Levels, Reject Rates, Direct Man-hour. \\
\hline Strategic Management & Sales Growth, Net Profits, ROI. \\
\hline
\end{tabular}


Table 1 also illustrates that the assessment of organizational overall performance is multidisciplinary due to the modern organization's web of relationships. Moreover, the different nature of these relationships makes the organizational performance a construct with more than one dimension. In the following paragraphs a brief analysis of some categorizations of performance measures and source of assessment is developed to support this point of view.

According to Cameron (1983), organizational performance may be assessed in terms of process, response, or impact. The first concentrates on the internal workings of an institution, the second attends to institution's responses to its surrounding environment, and the last attempts to assess the environment's reactions to institution's activities. Apparently using a similar framework, Watson (1975) suggests a threefold classification of performance measures: internal measures, interdependency measures and environmental measures. According to Watson (1975), the reference group for the development of interdependency measures are individuals within an organization who, in carrying out their tasks, rely on the individual being assessed (e.g., quality of raw material, employees commitment, purchase and delivery delays, material purchase price variance). For environmental measures, information is obtained from individuals located outside the organization, like customers and shareholders. The sources, from which interdependency and environmental measures are obtained, provide a basis for distinguishing them from internal measures. In others words, internal measures are indicators about the production process, capacity use and cost.

Apparently using a similar reasoning than Watson (1975), who proposes that performance should be assessed through two different sources; internal and external, Atkinson, Waterhouse and Wells (1997) go a step further and identify those sources of information to assess organizational performance as stakeholders and classify them into two groups. The environmental stakeholders (customers, owners, and the community) and the process stakeholders (employees and suppliers).

More recently, the Balanced Scorecard (BSC) framework, which presents the idea of translating mission and strategy into objectives and measures (Kaplan, 1983; Govindarajan, 1984; Kaplan and Norton, 1996), proposes that the organization's overall performance should be assessed through four perspectives: financial, customer, internal business process, learning and growth. These perspectives seem to have a similar performance assessment categorization than the former works, including owners, customers, process and employees, excluding, however, the environment In addition, the measures represent a balance between external measures for shareholders and customers, and internal measures of critical business processes; innovation, learning and growth. The 
measures are balanced between the outcome measures - the results from past efforts - most of them financial measures, and the measures that drive future performance, most of them operational and nonfinancial measures (Kaplan and Norton, 1996).

In the $\mathrm{BSC}$, the financial perspective is typically related to profitability, a traditional performance measure of investments owner. In the customer perspective, the framework suggests that managers identify the customer and market segments in which the business unit will compete and then create performance measures of the unit's performance in these targeted segments. The internal business process perspective proposes the identification of the critical internal processes in which the organization must excel. It relates supplier, employee and customer performance measures to the idea of the value chain model, which encompasses three principal business processes: innovation, operation and post-sales service. The last perspective, learning and growth, suggests that managers identify the infrastructure that the organization must build to create long-term growth and improvement, which is related to employee-based measures like employee satisfaction, employee retention, employee training, and employee skills.

The above analysis of the balanced scorecard framework and its comparison with the other categorizations of performance measures indicates the apparent absence of the environment (or community) perspective. This perspective is identified as the performance dimension assessed in terms of impact, according to Cameron (1983), or the environmental measures, according to the classification given by Watson (1975). This absence was already observed by Atkinson, Waterhouse and Wells (1997, p. 26), in the following statement:

"Kaplan and Norton [regarding The Balanced Scorecard] developed a model of how process results create customer satisfaction that, in turn, creates owner results. While we have no basic quarrel with this process approach to performance measurement, we feel that it is incomplete because it fails to [...] identify the role of the community in defining the environment within which the company works".

The authors also point out (Atkinson, Waterhouse and Wells, 1997) as a primary measure for the stakeholder group called community, the organizations public image. The public image of an organization is an abstract construct, whose measurement depends on the values, perception and judgement of the community surveyed. The same happens with customer satisfaction and employee commitment, which were pointed out by the authors as primary measures of customers and employees respectively. 
Hence, assuming that organizational overall performance is not a concept ${ }^{(3)}$, but a construct ${ }^{(4)}$, in terms of assessment. This section ends with the statement that organizational performance may be a construct whose overall assessment depends on three main dimensions:

the internal process,

. the organizational response to the external environment, and

. the environment's reaction related to the organization contribution.

The assessment of organizational performance by these three performance dimensions may be enhanced through the performance measures of activities and relationships performed by the organization with its stakeholders. The stakeholder group encompasses owners, customers and community as external stakeholders, and suppliers and employees as internal stakeholders. Table 2 summarizes the four studies analyzed in this section to support the argument about the assessment of organizational overall performance in three main dimensions.

Table 2: The Dimensions of Organizational Performance

\begin{tabular}{|l|l|l|l|}
\hline Watson(1975) & Internal & Interdependency & Environmental \\
\hline Cameron (1983) & Process & Response & Impact \\
\hline $\begin{array}{l}\text { Kaplan and Norton } \\
(1996)\end{array}$ & Internal Business Process & Learning and Growth & Financial and Costumer \\
\hline $\begin{array}{l}\text { Atkinson, Waterhouse } \\
\text { and Wells (1997) }\end{array}$ & $\begin{array}{l}\text { Process } \\
\text { Stakeholders: } \\
\text { employees and suppliers }\end{array}$ & $\begin{array}{l}\text { Environment Stakeholders: } \\
\text { customers, owners and the } \\
\text { community. } \\
\text { (social re spons ability) }\end{array}$ \\
\hline
\end{tabular}

Additionally, the above review suggests that the narrowest conception of performance measurement, focusing exclusively on the use of simple outcome based financial measures that reflect mostly the fulfillment of the economic goals, might be replaced by a broader view of organizational performance. A broader conceptualization of organizational performance, for example, would include emphasis on indicators of operational performance (i.e., nonfinancial information) in addition to indicators of financial performance measures. Under this framework, it is logical to treat measures such as market-share, new product introduction, product quality, marketing effectiveness, manufacturing value-added, and other measures of technological efficiency within the scope of organizational performance. Following this line of reasoning, the next section presents a discussion, in the context of performance evaluation, about the interrelationships 
between control motivation mechanism, agency theory and dysfunctional behavior.

\section{How and to What Extent Is a Reward System Related to the PMS?}

Managers attempting to motivate superior performance among subordinates and within their organizations and units offer, very often, incentive compensation to their subordinates linked to the level of performance achieved. These written and/or unwritten promises (usually labeled as contracts ${ }^{(5)}$ ) of incentive compensation are called reward systems.

It is the expectancy theory that provides the theoretical framework for specifying and estimating individual motivation (Steers and Porter, 1991). On the other hand, the perspective provided by the theory of agency relationships provides researchers with a systematic way to think about incentive compensation plans and assumptions about the alignment among individual and organizational goals (Kaplan and Atkinson, 1998). Creating a framework which links expectancy and agency theory, behavioral accounting research has been examining the moderate effect of subordinate motivation on the relation between compensation contracting and individual performance, providing useful tools for organization control. Consistent with agency theory, the organization is modeled in terms of compensation contracts made under conditions of information asymmetry about the agent's input and about environmental effects on outcomes. Thus, it can be assumed that the organization's accounting information and PMS criteria play a critical role in the process of performance measurement, reward and motivation. Moreover, evidence confirming a positive relationship between motivation and performance has already been reported in the accounting literature (e. g., Brownell and McInnes, 1986; Shields and Young, 1993; Kaplan and Atkinson, 1998).

From the above behavioral perspective, it is possible to infer that motivation to perform is provided by the incentive compensation ${ }^{(6)}$, which makes the individual performance partly a function of the extent and effectiveness of reward systems. In other words, the argument here is that since reward systems (which depend on PMS to assess subordinate performance) have proven to be an effective mechanism to enhance motivation and individual performance, they may also have an indirect effect on organizational overall performance. However, the hypothesis that the aggregation of the individual's maximized performance will lead to the optimal organizational performance is still an issue to be investigated. An expected positive effect on the organizational overall performance may find support in the argument developed in the first section of this paper. It asserts that 
the internal process dimension of overall performance may be assessed through the measurement (observation) of the subordinate's performance. The proposition would be that, the higher the subordinate's performance, the higher the internal process dimension contribution to the organizational overall performance.

In addition, when evaluating subordinate performance, accounting information is often used alone or in conjunction with other information. In some circumstances it has been found that subordinates respond to such evaluation in a manner that would not be perceived by their superiors as being consistent with organizational objectives and, consequently, their behavior is often labeled dysfunctional (Ouchi, 1979; Hirst, 1981; Camman, 1987). In related literature, illustrations of dysfunctional behavior include resistance, rigid bureaucratic behavior, strategic behavior and invalid data reporting. It is also assumed that dysfunctional behavior is often undertaken by subordinates to assist them in shirking or in receiving favorable performance evaluations. In this sense dysfunctional behavior may have a negative impact on the organization's overall performance, which makes the relationship between reward systems and performance even more complex.

The subordinates' performance evaluation and reward systems are mechanisms of the organization control system used, as argued before, to influence individual and group behavior. These two different mechanisms may devise a control system with focus on performance evaluation measures. Therefore, the literature in behavioral accounting has shown that a control system with strong reliance on performance evaluation may lead subordinates to a higher level of dysfunctional behavior. Camman (1976), who studied the relationship between control systems and subordinate dysfunction, states that subordinate response represents dysfunction for the organization when time and energy are used in ways that have little organizational value. He also gave two illustrations of a subordinate's control dysfunction behavior:

\section{"Tactical responses}

Subordinates can respond to control systems use with a variety of tactical responses designed to keep control system results from hurting them. Planning work to keep measured performance high, spending time checking control system calculations to be sure no mistakes were made, and carefully documenting external events which effect the performance measures are all examples of tactical responses that have been identified in previous research.

Defensive orientation

Subordinates can respond to control system use by developing a defensive orientation which can reduce the validity of the information contained by 
the system. This orientation often includes setting low goals so that results will look good, worrying primarily about performance measures, not real performance, and altering the information which goes into the control system"(Camman, 1976, p. 302).

The work of Hirst $(1981,1983)$ also supports this idea. This author studied the relationship among uncertainty, reliance on accounting performance measures and the subordinate's dysfunctional behavior. He hypothesized that, in general, where task uncertainty is high (low), a medium to low (high) reliance on accounting performance measure minimizes the incidence of dysfunctional behavior. The results provide evidence that high reliance on an incomplete performance measure was more likely to lead to dysfunctional behavior than high reliance on a complete measure. The author assumes that a performance measure is incomplete when it reflects only some of the activities and/or outcomes associated with the task performed. One of his main conclusions is that when task uncertainty is high, the performance measure is more likely to be incomplete. The incompleteness of performance measures is also an issue related to the causeand-effect relationship between manager actions and results, which is explored later in this paper. Moreover, also according to Hirst (1983), the dysfunction occurs due to the unbalance between the level of environment uncertainty perceived by the subordinate and the performance measures used by the superior.

Another perspective about the relationship between reward systems and an organization's PES has been risen by Coates, Davis and Stacey (1995). These authors examined the propensity for short-termism within the organization's PES of large U.K., U.S. and German multinationals. Attention was focused on how the incorporation of managerial reward schemes may reinforce a potential bias toward short-termism behavior through interaction with the PMS. The manner in which the formal systems are applied and management attitudes towards them provided insights about the reasons of the alleged short-termist bias of U.K. and U.S. companies compared with their German counterparts. In this sense, one of the main contributions of this article is the identification it portrays of the relationship between managerial reward and PMS at different organization levels in different countries.

Finally, the issues about complete/incomplete measures and short-termism, as well as their relationship with dysfunctional behavior, provide some warnings about the necessary attention on the alignment between reward systems and PMS, as well as its potential impact on the organization's overall performance. Otherwise, reward systems may promote competition between subordinates where cooperation would have been preferable, and may encourage the manipulation of actions and reports so that decision takers and performance evaluations may become misinformed. 


\section{Why is PMS Criteria Definition a Difficult Task?}

Nowadays, in the information age, it has very often been said that one of the biggest threats for the organization's performance is the simple absence of the information necessary to take decisions. More serious, however, may be the cases where the wrong information has been used to take decisions. It leads the discussion about the inherent difficulties that managers face when attempting to set the correct PMS criteria for an organization. The main concern is about the potential impact on the accuracy of various decisions of reward and resource allocation, which are based on PMS. Based on the literature, three problems related to the difficult process of identification of the correct set of performance criteria will be discussed here: the manager perception about cause-effect relationship of their actions, the changing preferences of performance criteria in organizations over time and the organizational pursuit of contradictory preferences.

\section{Cause-Effect Relationships}

Kaplan (1984) first raised the issue of cause-effect relationship among manager actions and results in a performance evaluation context when he was studying a petrochemical industry. Later, Kaplan and Norton (1996, p. 30) developed the balanced scorecard framework and argued: "the measurement system should make the relationships (hypotheses) among objectives and measures in the various perspectives explicit so that they can be managed and validated".

It seems simple, but it is extremely difficult to attribute causality to organizational actions when a myriad of interacting elements exists simultaneously in an uncertain environmental niche. Three aspects may be enough to illustrate this point of view. First, the relationships among the organization and its stakeholders takes place in a complex and uncertain environment which very often makes complex the task of identifying in advance the results (the effects) of managerial works or decisions (potential causes). Second, some organization tasks require the cooperation of managers of different sub-units. In this case, the stakeholder's interdependence makes it difficult to isolate and consequently evaluate the effects of a specific unit, manager, activity or resource use. The consequence is that sometimes, the assessment of performance indicators inevitably becomes subjective or does not reflect accurately the relationship input/ output. Third, some aspects of performance cannot be measured and/or translated into monetary information. Although, they may often be very important to the organization, the accounting literature provides evidence that there is a tendency 
in the design of PMS for financial measures to dominate quantitative nonfinancial and qualitative measures.

Considering these constraints, measurement issues have helped refocus the research in performance measurement toward the use of nonfinancial performance indicators. Morissette (1996) and Ittner, Larcker and Rajan (1997), among other authors, suggest that traditional financial performance measures, such as cost per unit or profit which are unavailable on a timely basis, are often considered by managers as too aggregated and too late for the organization's monitoring purposes. Morissette (1996) also provides evidence that nonfinancial measures are perceived to be alternative or supplemental indicators that overcome the argued problems of financial measures. However, he noticed that the nonfinancial information level of use depends on the manager's perception of the underlying casual-effect relationship between nonfinancial indicators and the organization financial performance, and the manager's ability to focus on a few critical causeeffect relationships.

In the same direction, Fisher (1992) argues that the recent rise of nonfinancial performance measures represents an attempt to reassert the primacy of operations over financial measures. This author followed some implementation of nonfinancial measurement and control systems at several high-technology manufacturing plants and provided evidence that, by using nonfinancial measures, managers attempt to track progress on the actionable steps that lead to a company's success in the market.

Thus, it is the constant presence of uncertainty and complexity in the organization's relationships that sometimes makes the identification of optimization criteria something subjective and ambiguous. The above discussion however, not only sheds light on how PMS quality may be affected by imprecise cause-effect relationship ${ }^{(7)}$, but also reinforces the idea that the basic problems surrounding organizational performance evaluation and PMS design may have been criteria problems that correctly reach the cause-effect relationship of organization's actions.

\section{Changing Preferences of Performance Criteria}

The second issue concerning the correct set of PES criteria is the fact that the bases, in the minds of organizational members for judging the ideal organization performance, change over the organizational life-cycle states. Consequently, it is expected that the organization's performance drivers and, therefore, PMS criteria, may change dramatically over time. Before raising the argument about why criteria may change over time, it is important to explain the adopted 
distinction between performance indicators ${ }^{(8)}$ (or outcome measures) and performance drivers, as well as their potential connection with the organization's strategy.

According to Kaplan and Norton (1996, p. 149):

\begin{abstract}
"generic measures tend to be core outcome measures, which reflect the common goals of many strategies, as well as similar structures across industries and companies. These generic outcome measures tend to be lag indicators, such as profitability, market share, customer satisfaction, customer retention, and employee skills. The performance drivers, the lead indicators, are the ones that tend to be unique for a particular business unit's strategy; for example, the financial drivers of profitability, the markets segments in which the unit chooses to compete, and the particular internal processes and learning and growth objectives that will deliver the value propositions to target customers and market segments".
\end{abstract}

In order to highlight the above distinctions, we might say that performance drivers are defined in conformity with specific settled strategies whose successful implementation is monitored and communicated through the achievement of performance indicators. The same idea of necessary alignment and hierarchy among performance drivers and performance indicators is found in the work of Atkinson, Waterhouse and Wells (1997), where they are labeled as primary and secondary performance measures, respectively.

Thus, if on one hand, organizations may have an alignment among strategies, performance drivers and performance indicators, and on the other hand, assuming that an organizational strategy is a dependent variable of the organization's environment uncertainty (which is strongly supported by the related literature), it will be a reasonable hypothesis that performance criteria will evolve and change whenever strategies changes. The implication is the requirement of regular review of the PMS design. Studying the assessment of organizational effectiveness, Cameron and Whetten (1983) provide empirical evidence that the preferences of members of organizations change over organizational life-cycle states. According to them, in the early stages of the organization's development, members preferred criteria of effectiveness that emphasized individual levels of performance, such as succeeding at personal tasks and acquisition of inputs. In later stages of development, the former indicators became unimportant and members' preferences changed toward organizational-level outputs, such as total organization productivity.

The above discussion illustrates how managers' changing preferences are important to the design and success of PMS and how critical they may be to the 
assessment of organizational performance. In other words, due to the strategies and organization life cycle, performance criteria and the relevance of each group of stakeholders may differ markedly depending on when the assessment is made. Moreover, it does not only affect performance measurement process, but also its comparisons within units and among organizations.

\section{Organizational Pursuit of Contradictory Preferences}

The third issue related to the definition of performance criteria is related to the simultaneous pursuit by organizations of contradictory preferences. First of all, it is important to emphasize that the issue of contradictory preferences differs from the issue of conflict of interest or bounded rationality ${ }^{(9)}$ among organization stakeholders. The issue of contradictory preferences is related to the question of how good performance is to be defined. In other words, what are the organization's preferences to qualify its performance in a specific dimension as bad or good? At any one time the dimensions ${ }^{(10)}$ being emphasized to be good or bad are likely to be multiple, partially conflicting and often ambiguous. More precisely, since the extent that cause-effect relationships are not fully known by managers, actions designed to achieve strategies and goals settled might be debatable and contradictory due the contradictory preferences and perceptions held by individuals in the organizations. It is not unusual for individuals in organizations to prefer growth and stability, standards and flexibility, high capital investment and high returns to stockholders, autonomy and control, etc. Moreover these paradoxes $^{(11)}$ are supported by some apparently contradictory attributes of postindustrial organizations like expertise and high generality of roles; flexibility and interdependency; stability and adaptability; long-term planning and innovation. According to Cameron and Whetten (1983), organizations frequently pursued these different domains of activities simultaneously, but doing better in one domain resulted in doing worse in another domain. Contradictory preferences can exist at the same time because one domain of activities may be independent of another. When they are not independent, the authors conclude: "'incrementalism' is practiced (i.e., trading off one set of preferences against another), 'satisficing' strategies are pursued (i.e., fulfilling all preferences to only a limited extend), or 'sequencing' occurs (i.e., alternating emphasis among preferences)" (Cameron and Whetten, 1983, p. 15).

Assuming that contradictory preferences may be independent of each other and their pursuit by organization are not incompatible, their integration seems to be the new challenge for the design of PMS. This integration also seems to be a new field for further investigation in the area of performance evaluation, and its progress is apparently dependent of different views about the nature and origin 
of organizational strategies and goals ${ }^{(12)}$, new perspectives of the nature of relationships between an organization and its environment, and formal measurement of unlike aspects of organizational performance, including the use of nonfinancial information.

\section{Final COMMenTS}

In essence, the above theoretical analysis of some critical issues about the nature and design of performance measurement systems (PMS), corroborates the idea that an organization's performance measures, strategies, and actions are complementary and that their alignment is an essential ingredient in the formula for organizational success. In this regard and based on related literature, this paper addressed the need for integration proposing that a better assessment of organizational overall performance may be enhanced when considering three dimensions: the internal process, the organizational response to external environment and the environment reaction related to the organization contribution. The authors of the present article believe that further research may lead to a framework that will help investigate empirically the performance assessment through those three dimensions.

Moreover, the quest for integration among performance measures, strategy and actions, or even among the three dimensions proposed, has disclosed for managers and researchers the myriad of complexity, uncertainty and interacting elements that is an organization. The discussion of some of these complex issues was also addressed in this paper. The problems of incomplete performance measures and short-termism were raised to analyze and emphasize the interdependence between reward systems and PMS. It is proposed that an alignment between them, may reduce potential dysfunctional behavior. Discussing the cause-effect issue, this paper supported the argument that the basic problems surrounding organizational performance evaluation and PMS design, may have been criteria problems that correctly reach the cause-effect relationship of an organization's actions and results. The organization's pursuit of changing and contradictory preferences was discussed in a performance criteria definition context. In this direction, this article also defended the idea that performance criterion and constituency groups' relevance may differ markedly along the organization life cycle, affecting the performance measurement process and its comparability. 


\section{Figure 1: The Link between Performance Measurement and Reward Systems}

\section{Control System}

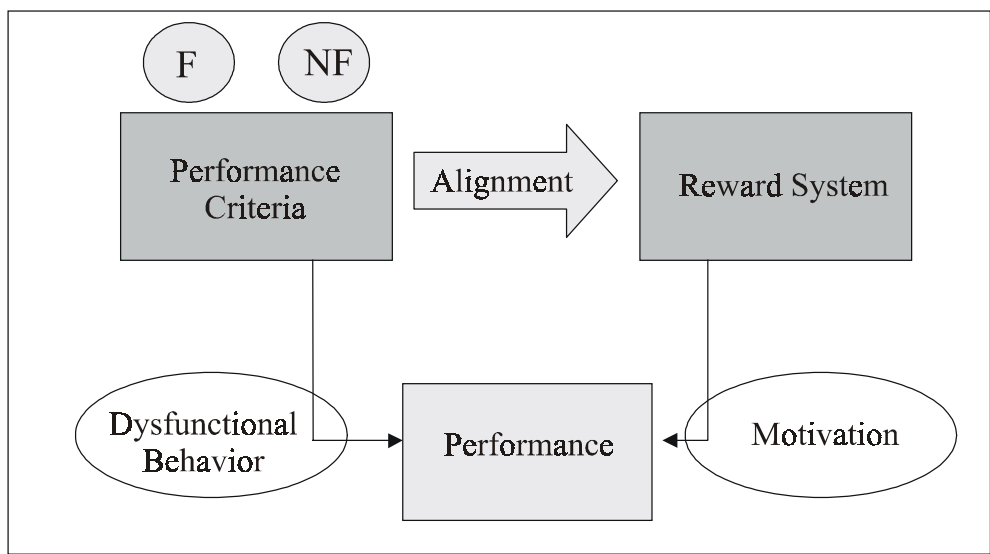

$\mathrm{F}=$ Financial indicators

$\mathrm{NF}=$ Nonfinancial indicators

\section{NOTES}

${ }^{1}$ Different models of organizations can be found in the related literature (among others the garbage can, open systems and rational entities in pursuit of goals). This identification seems important since different models of organization lead to different models of performance evaluation.

${ }^{2}$ In the behavioral accounting literature it is usually identified as Reliance on Accounting Performance Evaluation (RAPM).

${ }^{3}$ Concepts, in terms of empirical research, are considered variables that can be defined and exactly specified by observing objective events.

${ }^{4}$ Constructs cannot be exactly specified or directly observed as concepts are. In other words, constructs have their boundaries not precisely drawn. Their assessment is possible through the abstractions that exist in the peoples' mind, but they have no objective reality. They exist only because they are inferred from the results of observable phenomena. Traditional examples of constructs broadly assessed in the same way by literature are: leadership, users' needs, intelligence, motivation etc.

${ }^{5}$ See Merchant (1989).

${ }^{6}$ According to Steers and Porter (1991), it is a necessary condition, that subordinates perceive the link between their performance (or their effort) and the reward they will receive. Otherwise the effect motivation is not effective. 
${ }^{7}$ The managers' focus on critical cause-effect relationships is a recent research field and has been called manager's mental model (Calori, Johnson and Sarnin, 1994).

${ }^{8}$ Performance indicators, which can be financial or nonfinancial, are considered by the author of this paper as measures to assess the result or contribution generated by the use of any activity, resource or task. For this reason, the author assumes that performance indicators as used in this paper coincide with the idea of outcome measures provided by Kaplan and Norton (1996).

${ }^{9}$ These issues were addressed by Cyert and March (1963), among other authors.

${ }^{10}$ Early discussed in section 1 of this paper.

${ }^{11}$ Paradoxes differ in nature from other similar concepts often used as synonyms such as dilemma, irony, inconsistency, dialectic, ambivalence, or conflict. Paradox differs from each of these concepts in that no choice need to be made between two or more contradictions. Both contradictions in a paradox are accepted and present. Both operate simultaneously (Cameron, 1986).

${ }^{12}$ Already started by Kaplan and Norton (1996) with the balanced scorecard framework.

\section{REFERENCES}

ATKINSON, A. A.;

WATERHOUSE, J. H.;

WELLS, R. B.

A stakeholder approach to strategic performance measurement.

Sloan Management Review, p. 25-37, Spring 1997.

BROWNELL, P.;

MCINNES, $M$.

Budgetary participation, motivation and managerial performance. The Accounting Review, p. 587603, October 1986.

CALORI, R.;

JOHNSON, G.;

SARNIN, P.

CEOs' cognitive maps and the scope of the organization. Strategic

Management Journal, v. 15, n. 6, p. 437-457, 1994.
CAMERON, K.;

WHETTEN, D.

Organizational effectiveness : a comparison of multiple models. London : Academic Press, 1983.

CAMMANN, C.

Effects of the use of control s y s t e m s. A ccounting, Organization and Society, v. 1, n. 4, p. 301-313, 1976.

COATES, J.;

DAVIS, T.;

STACEY, R.

Performance measurement systems, incentive reward schemes and short-termism in multinational companies : a note.

Management Accounting Research, v. 6, p. 125-135, 1995. 
CYERT, R. M.;

MARCH, J. G.

A behavioral theory of the firm. Englewood Cliffs, NJ : PrenticeHall, 1963.

FISHER, J.

Use on non financial performance measures. Journal of Cost Management, p. 31-38, Spring 1992.

GOVINDARAJAN, V.

Appropriateness of accounting data in performance evaluation : an empirical evaluation of environmental uncertainty as an intervening variable. Accounting, Organizations and Society, v. 9, n. 2, p. 125-135, 1984.

HIRST, M. K. H.

Accounting information and the evaluation of subordinate performance : a situational approach. The Accounting Review, v. LVI, n. 4, p. 771-784, October 1981.

Reliance on accounting performance measures, task uncertainty, and dysfunctional behavior: some extensions. Journal of Accounting Research, v. 21 , n. 2, p. 596-605, Autumn 1983.
ITTNER, C. D.;

LARCKER, D. F.;

RAJAN, M. V.

The choice of performance measures in annual bonus contracts. The Accounting Review, v. 72, n. 2, p. 231-255, Apr. 1997.

KAPLAN, R.

Measuring manufacturing performance : a new challenge for management accounting research. The Accounting Review, v. LVIII, n. 4, p. 686-705, 1983.

Yesterday's accounting undermines production. Harvard Business Review, v. 62, p. 95-101, 1984.

KAPLAN, R.;

ATKINSON, A. A.

Advanced management accounting. Englewood Cliffs, NJ : Prentice-Hall, 1998.

KAPLAN, R. S.;

NORTON, D. P.

The balanced scorecard : translating strategy into action. Boston, MA : Harvard Business School Press, 1996.

MERCHANT, K. A.

Rewarding results. Boston, $\mathrm{MA}$ : Harvard Business School Press, 1989. 
MORISSETTE, R.

Toward a theory of information choices in organizations : an integrative approach. Waterloo, 1996. Doctoral Thesis University of Waterloo, Canada.

OUCHI, W. G.

A conceptual framework for the design of organizational control mechanisms. Management Science, v. 25, n. 9, p. 833-848, 1979.

SHIELDS, M. D.;

YOUNG, M. S.

Antecedents and consequences of participative budgeting : evidence on the effects of asymmetrical information. Journal of Management Accounting Research, v. 5, p. 265-280, Fall 1993.

STEERS, R. M.;

PORTER, L. W.

Motivation and work behavior.

5. ed. New York : McGraw-Hill, 1991.

WATSON, D. J. H.

Contingency formulations of organization structure: implications for management accounting. In: LIVINGSTONE, J. L. (Ed.). Managerial accounting : the behavioral foundations. 1975 . p. 65-80. 